\title{
Design of A Compact C-Shape Multiband Frequency Reconfigurable Antenna
}

\author{
Karam Mudhafar Younus ${ }^{1}$ \\ \{1karam.younus@uoninevah.edu.iq $\}$ \\ ${ }^{1}$ College of Electronics Engineering, Ninevah University, Mosul, Iraq
}

\begin{abstract}
In this paper, a Multiband-Frequency-Reconfigurable Antenna with a small compact size $\left(20 \times 35 \times 1.6 \mathrm{~mm}^{3}\right)$ is presented. The designed antenna can work effectively under the following modes: two modes of single band and one mode with dual bands. The reconfigurability has been achieved accurately by switching (ON/OFF) the incorporated PINdiodes. The designed antenna is tested under the following applications; 3G, 4G AWS1 (1700$2100 \mathrm{MHz})$, Wireless-Area-Network $(2.45 \mathrm{GHz}$ and $5 \mathrm{GHz})$ and Worldwide Interoperability for Microwave Access (3.5 GHz). The designed antenna is fabricated as a C-shape monopole placed on the commercial FR-4 substrate. The antenna is simulated using the student version of the Computer Simulation Technology (CST-MWS). The three modes match the Reflection Coefficient $\left(S_{11}\right)<-10 \mathrm{~dB}$ and the efficiency $>84 \%$. The average gain ranged from 1.9 to $3 \mathrm{dBi}$. A prototype has been fabricated and measured. The comparison between the fabricated and simulated antenna results, such as $S_{11}$, Efficiency, and gain, are illustrated. A good agreement between the results has been noticed which validates the design concepts.
\end{abstract}

Keywords: Frequency-Reconfigurable, Multiband,3G, 4G, WiMAX, WLAN, CST-MWS, PIN-Diodes.

\section{Introduction}

Currently, the lower spectrum band witness obvious congestion, due to the continuously increasing demands for new applications especially with the emerging of 5G wireless communication systems. To cope with these demands, wideband antennas that operate in multiple bands can be used. However, with such types of antennas, the interferences will be the main challenging issue. Consequently, the reconfigurable antennas have gained more interest and they proofed to be good candidates for wireless applications. These types of antennas can satisfy the needs of the market. However, their performances are found to be changeable with the design parameter such as microstrip size, and the used switching type. Moreover, the relatively high cost of designing such antennas may be also the main limiting factor. In the literature, it can be found more than one standard has been integrated into one antenna. For instance, the Wireless Area Network (WLAN) and (WiMAX) standards have been integrated into one antenna. This suggests the use of dual-band monopole antenna for the WiMAX systems as can be seen in [1]. In [2], a planar inverted-F antenna with multi-band for the Wireless Wide Area Network system has been 
presented. In [3] a patch antenna with multi-band and multi-polarization statuses has been presented and in [4], an antenna with dual-loop for the $(2.4 / 5.2 / 5.8) \mathrm{GHz}$ has been proposed.

Several types of slot antennas have been designed for the ISM, WLAN and WiMAX applications in the $2.4 \mathrm{GHz}(802.11 \mathrm{~b} / \mathrm{g} / \mathrm{h}), 5 \mathrm{GHz}(802.11 \mathrm{a} / \mathrm{n})$ and $3.5 \mathrm{GHz}$ (IEEE 802.16) operating bands [5-6]. Also, multiband antennas with various shapes have been proposed in [7-11] where a Dual-band mode (2.45 and 5.8 GHz) B-shaped antenna is presented in [7]. In [8] an Eshaped monopole antenna for WLAN applications has been presented, similarly, a dual-band antenna is proposed in [9] with an F-shaped for WLAN and radio frequency identification (RFID) applications. A C-shaped monopole antenna is designed in [10], which have the ability to work for dual-mode $(2.4$ and $5.8 \mathrm{GHz})$ bands. Also, A Tri-band reconfigurable slot antenna has been presented in [11].

This work presents a C-shaped monopole antenna with a small compact size $\left(20 \times 35 \times 1.6 \mathrm{~mm}^{3}\right)$ to operate over multiple and various spectrum bands. The frequency can be reconfigured and the designed antenna can work on the following bands: 3G, 4G AWS1 (1700-2100 MHz), (WLAN) $(2.45 \mathrm{GHz}$ and $5 \mathrm{GHz})$ and WiMAX $(3.5 \mathrm{GHz})$. The reconfigurability was achieved accurately by switching (ON/OFF) the mounted PIN-Diodes. This paper has the following order: Section 2 describes the design methodology. The results of the simulated and fabricated antennas are presented in section 3. The performance of the designed antenna is compared with other related and existing designs in section 4 . The last section concludes the paper.

\section{The Designed Antenna}

The antenna under investigation is designed and simulated using the student version CST-MWS simulation program as shown in Figure 1. It is designed to have a shape similar to the English letter (C) where the PIN diode switches can be easily incorporated and reconfigured. The design consists of a monopole on the antenna face. The substrate has been chosen to be the commercial FR-4 with relative permittivity of 4.3 , the thickness is $1.6 \mathrm{~mm}$ and loss tangent of 0.025 . The design has a compact size with $\left(20 \times 35 \times 1.6 \mathrm{~mm}^{3}\right)$ dimensions. The proposed antenna has been designed using the transmission line model theory, which is used to calculate the effective length $\left(\lambda_{\mathrm{e}}\right)$ of the monopole. The considered antenna consists of three monopoles as illustrated in Figure 1. The dimensions of the proposed antenna are listed in Table 1.

The length of the proposed monopoles has been chosen based on the $\left(\lambda_{\mathrm{e}} / 2\right)$ of the proposed operation bands. These lengths have been optimized by the Trust Region Framework Algorithm which is a numerical optimization for solving nonlinear programming problems. The effective length of each monopole has been calculated based on the following equations:

$$
\lambda_{e}=\frac{c}{f_{0} \sqrt{\varepsilon_{e}}} .
$$




$$
\begin{gathered}
\varepsilon_{e}=\frac{\varepsilon_{r}+1}{2}+\frac{\varepsilon_{r}-1}{2}\left(\sqrt{1+\frac{12 h}{w}}\right)^{-1 / 2} . \\
\text { MonopoleLength }=\frac{\lambda_{e}}{2} .
\end{gathered}
$$

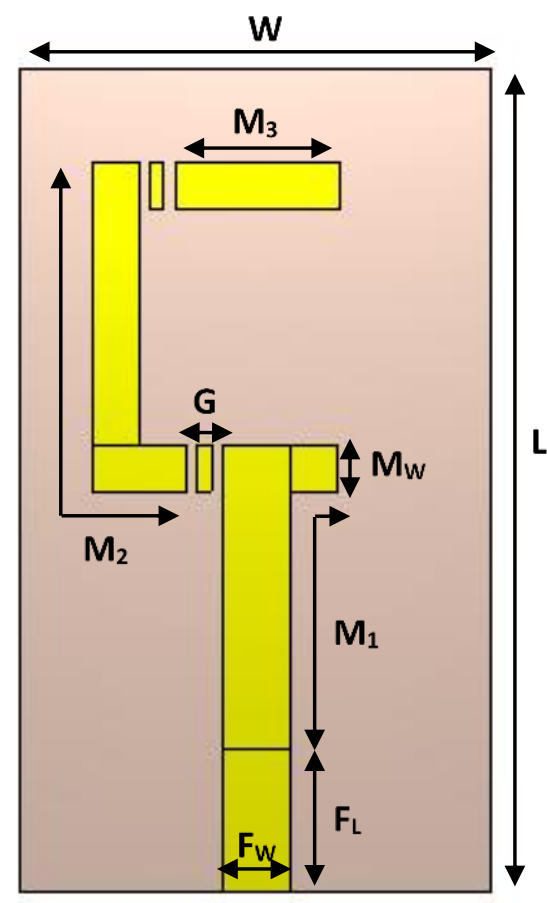

(I)

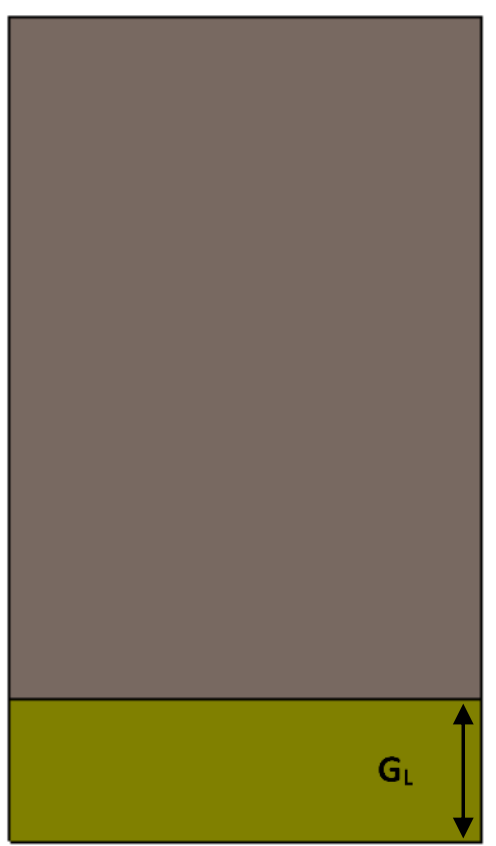

(II)

Fig. 1. C-Shape Frequency Reconfigurable Antenna. (I) Front-View, (II) Back-View.

Table. 1: The designed antenna parameters.

\begin{tabular}{c|c|c|c|c|c|c|c|c|c}
\hline Parameter & $\mathrm{W}$ & $\mathrm{L}$ & $\mathrm{G}_{\mathrm{L}}$ & $\mathrm{F}_{\mathrm{L}}$ & $\mathrm{M} 1$ & $\mathrm{M} 2$ & $\mathrm{M} 3$ & $\mathrm{~F}_{\mathrm{W}}$ & $\mathrm{G}$ \\
\hline Value $(\mathrm{mm})$ & 20 & 35 & 6 & 6 & 15.3 & 16 & 7 & 2.88 & 1.5 \\
\hline
\end{tabular}

Where $\lambda_{e}$ is the effective wavelength, $\varepsilon_{e}$ is the effective relative permittivity. Table 2 . shows both the calculated and optimized $\left(\lambda_{e} / 2\right)$ values. 
Table 2. A comparison between the calculated and optimized $\lambda_{\mathrm{e}} / 2$ values.

\begin{tabular}{c|c|c}
\hline Operation Bands & Calculated $\lambda_{\mathrm{e}} / 2$ in $(\mathrm{mm})$ & Optimized $\lambda_{\mathrm{e}} / 2$ in $(\mathrm{mm})$ \\
\hline $1.7-2.1 \mathrm{GHz}$ & 38 & 38.1 \\
\hline $2.45 \mathrm{GHz}$ & 29.5 & 31 \\
\hline $3.5 \mathrm{GHz}$ & 20.65 & 15.3 \\
\hline $5.2 \mathrm{GHz}$ & 14.46 & Combination of Monopole 1 and 2
\end{tabular}

A gap of $1.5 \mathrm{~mm}$ centered by a thin-slot has been inserted within the C-shape radiating elements in order to mount the PIN-Diodes switches and their setup components.

In the CST-MWS, the PIN-Diodes have been considered as switches based on their operation modes. For the forward biasing, the PIN-Diodes consider as close switch (short circuit) and can be modelled by a series of a very low resistor $\left(R_{S}\right)$ and an inductor $(L)$. On the other hand, the PINDiode considered as an open switch (open circuit) in the reverse bias mode and it is constructed by an inductor $(L)$, a parallel high resistor $\left(R_{S}\right)$ and a capacitor $\left(C_{R}\right)$. Figure 2 . shows the equivalent circuit of the PIN-Diode for both statuses (ON/OFF).

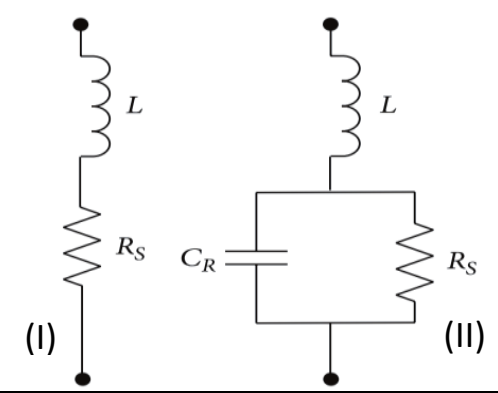

Fig. 2. The equivalent circuit of the PIN-Diode. (I) Forward bias; (II) Reverse bias.

Figure 3. shows the fabricated antenna. The antenna is fed by an SMA connector. In order to set up a diode, a blocking DC capacitor with $470 \mathrm{pF}$ is needed. Besides an inductor of $125 \mathrm{nH}$ which is used as RF chock blocker. Each diode has to be supplied with a biased voltage. The ON state can be realized (practically) by placing a copper strip or soldering the gap between the two ends. Thus, this condition has been considered for this proposed design [11]. 


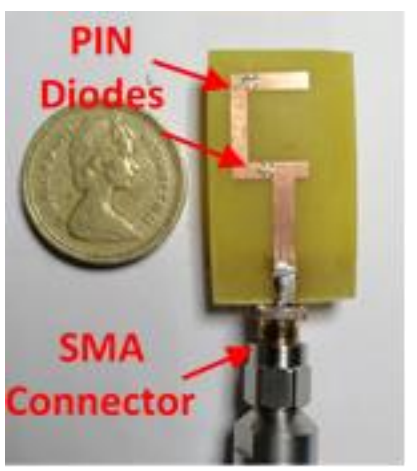

(I)

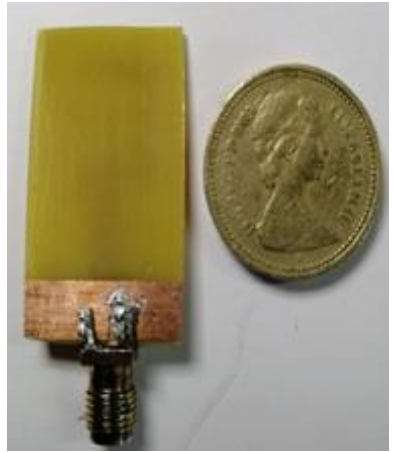

(II)

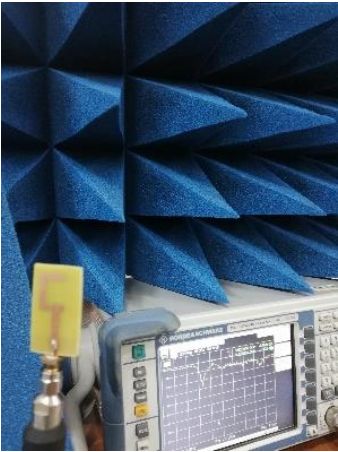

(III)

Fig. 3. Fabricated antenna; (I) Front-view. (II) Back-view. (III) Antenna under-test

\section{The Measured and Simulated Results}

In this section, the performance of the designed antenna is verified experimentally and compared to those simulated results. The performance in terms of gain, efficiency, Reflection coefficient $\left(S_{11}\right)$, Electric-field distribution and the Farfield radiation pattern are computed and compared against measurements. The reconfigurability has been achieved by turning the PIN-Diode Switches ON or OFF. Table 3. Show the switches statuses and their corresponding operation bands.

Table 3. Proposed Antenna Operation Modes.

\begin{tabular}{c|c|c|c}
\hline Operation Modes & $\mathrm{SW}_{1}$ & $\mathrm{SW}_{2}$ & Frequency Bands $(\mathrm{GHz})$ \\
\hline Mode 1 & OFF & $\mathrm{OFF}$ & 3.5 \\
\hline Mode 2 & ON & OFF & $2.45,5$ \\
\hline Mode 3 & ON & ON & $1.7,2.1$ \\
\hline
\end{tabular}

In mode 1 , the antenna will resonate at $3.5 \mathrm{GHz}$, the $\mathrm{SW}_{1}$ and $\mathrm{SW}_{2}$ are both in OFF status. Figure 4. shows the $S_{11}$ coefficient. It is clear that the antenna has an $S_{11}<-16 \mathrm{~dB}$ for the simulated and less than $-20 \mathrm{~dB}$ for the measured antenna. The bandwidth is found to be more than $840 \mathrm{MHz}$. 


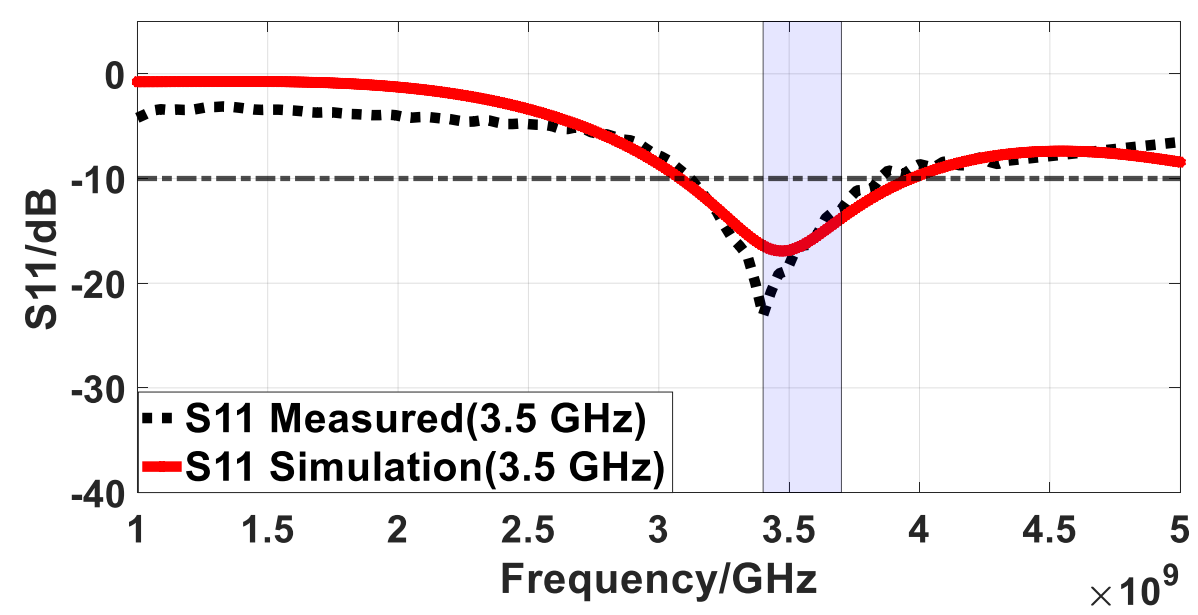

Fig. 4. Simulated and measured $S_{11}$ values versus frequency when $S_{1}$ and $S_{2}$ are both $O F F$.

When $\mathrm{SW}_{1}$ is turned $\mathrm{ON}$ and $\mathrm{SW}_{2}$ turned $\mathrm{OFF}$, the antenna will work in the second mode which includes two operation bands for the WLAN applications $2.45 \mathrm{GHz}$ and $5 \mathrm{GHz}$. Figure 5. shows the $\mathrm{S}_{11}$ coefficient. It is clear that the antenna has simulated and measured $S_{11}$ values less than $-20.8 \mathrm{~dB}$ and $-17 \mathrm{~dB}$, respectively at $2.45 \mathrm{GHz}$, while these values are less than $-20 \mathrm{~dB}$ and $-16.8 \mathrm{~dB}$ at $5 \mathrm{GHz}$ band. Indeed, the bandwidth for the two-operation bands has been covered.

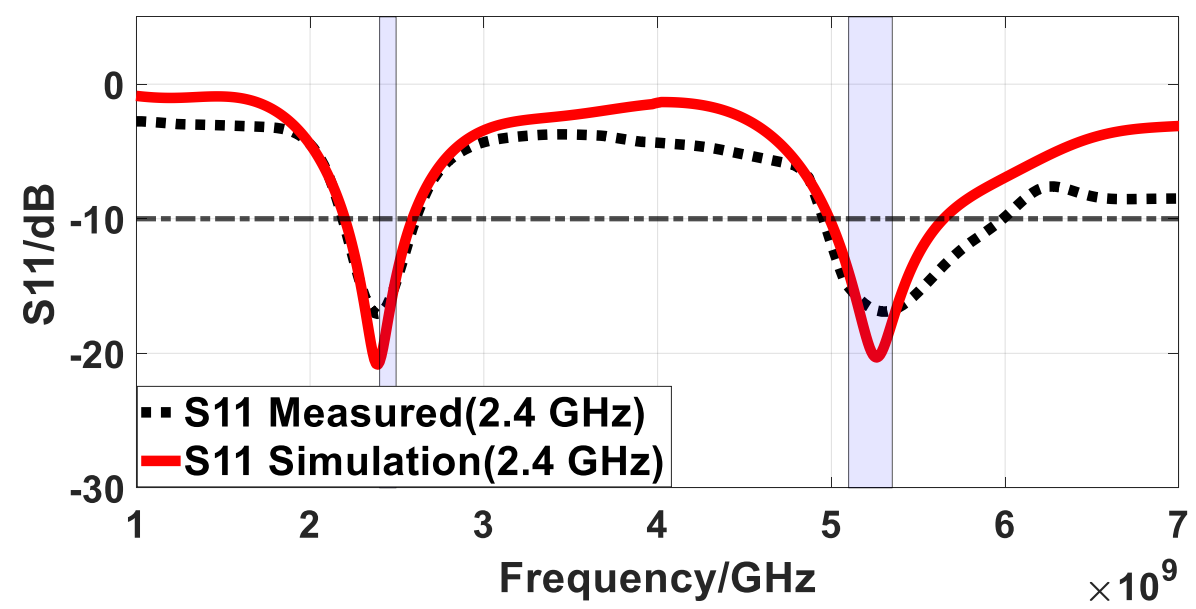

Fig. 5. Simulated and measured $S_{11}$ values versus frequency when the $\mathrm{SW}_{1}$ is $\mathrm{ON}$ and $\mathrm{SW}_{2}$ is $\mathrm{OFF}$. 
Finally, when the two switches are turned ON, the antenna operates at the range of (1700 to 2100) $\mathrm{MHz}$, which represents the $3 \mathrm{G}, 4 \mathrm{G}$ AWS1 mobile applications. Figure 6. shows the $\mathrm{S}_{11}$ coefficient. It is obvious that the antenna has an $\mathrm{S} 11<-25 \mathrm{~dB}$ and the bandwidth covers the frequency range from $1.6 \mathrm{GHz}$ to less than $2.4 \mathrm{GHz}$

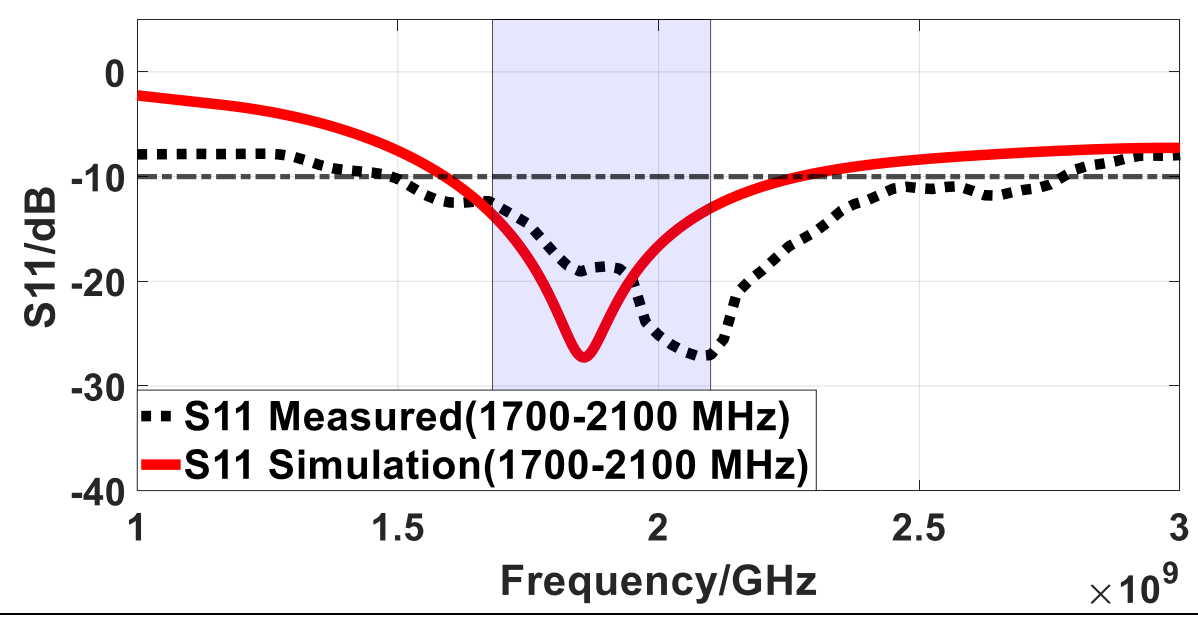

Fig. 6. Simulated and measured $S_{11}$ values versus frequency when both the $\mathrm{SW}_{1}$ and $\mathrm{SW}_{2}$ are $\mathrm{ON}$.

Table 4. shows the simulated gain and efficiency for the thee operation modes.

Table 4. Operation Modes' gain and Efficiency.

\begin{tabular}{c|c|c}
\hline Operation Modes & Gain $(\mathrm{dB})$ & Efficiency (\%) \\
\hline Mode 1 & 1.9 & 89 \\
\hline Mode 2 & 3 & 84 \\
\hline Mode 3 & 2.1 & 90 \\
\hline
\end{tabular}

The Simulated and normalized E-field at the three modes is shown in Figure 7. which shows the effective resonant lengths at the respective frequency. 


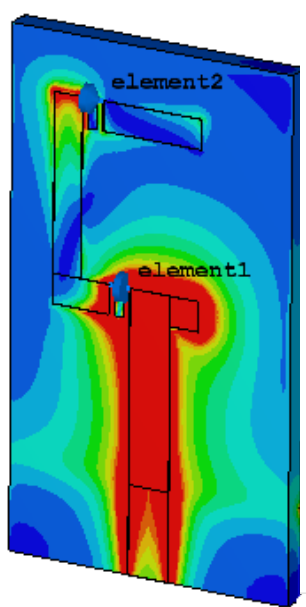

(I)

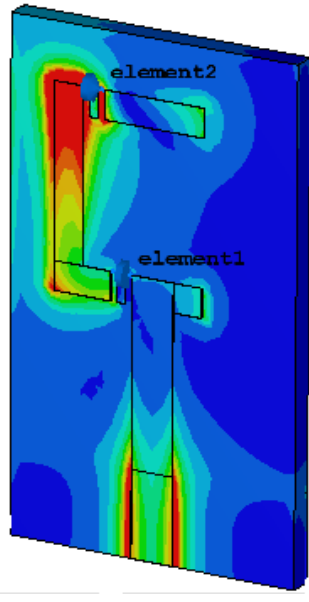

(II)
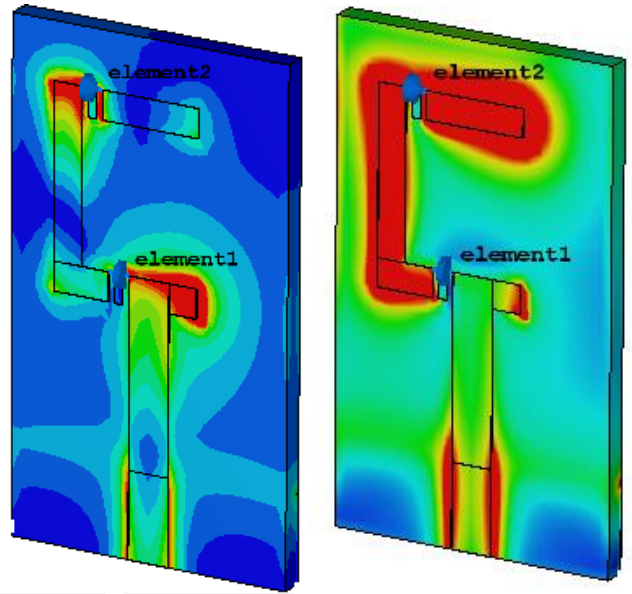

(IV)

Fig. 7. The proposed antenna electric-field distribution at: (I) $3.5 \mathrm{GHz}$. (II) $2.45 \mathrm{GHz}$. (III) 5 GHz. (IV) 1.7 $2.1 \mathrm{GHz}$.

Figure 8. shows the simulated and measured radiation patterns of the designed antenna for the three modes.

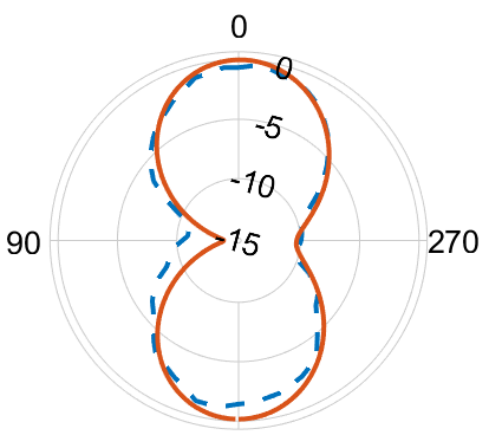

180

- -Measured -Simulated

(I)

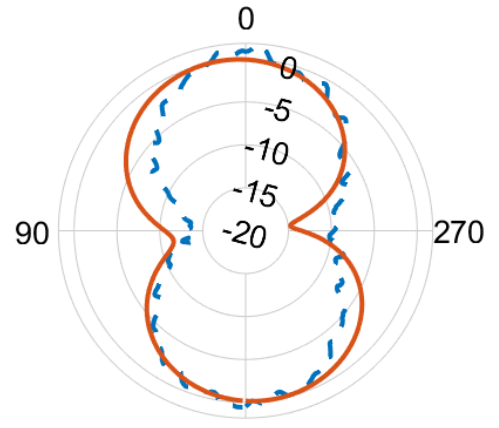

180

-Measured -Simulated

(II) 


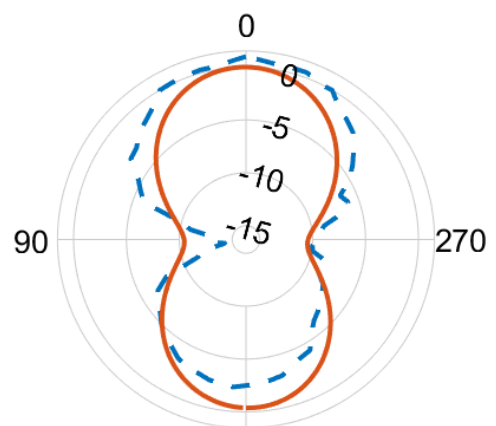

180

\section{- -Measured -Simulated}

(III)

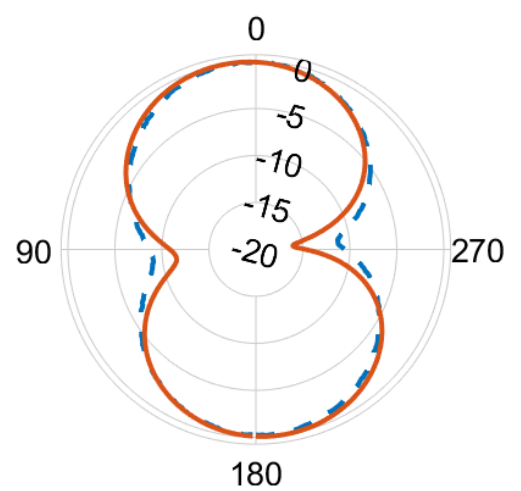

- Measured - Simulated

(IV)

Fig. 8. Antenna Pattern for the Simulated and Measured antenna for all frequency modes: (I) $3.5 \mathrm{GHz}$ (mode 1), (II) $2.45 \mathrm{GHz}$ (mode 2), (III) $5 \mathrm{GHz}$ (mode 2), (IV) 1.7-2.1 GHz (mode 3)

\section{Comparison with Some Existing Antennas}

The performance of the proposed antenna is compared with other existing multi-band antennas that were designed and used for 3G, 4G, WLAN, WiMAX applications. Table 4 demonstrates a comparison in terms of the size of the antenna, the number the operation bands, operation frequencies and finally the gain.

From this table, it is clear that the proposed antenna has the highest gain compared to those antennas in $[12,13,15,16]$, and lower than that of [14]. However, the proposed antenna has a smaller size. It is worth mention that all the antennas in Table 5 are fabricated with FR-4 substrate, $\varepsilon_{\mathrm{r}}=4.3$, and height of $1.6 \mathrm{~mm}$.

Table 5. Comparison between the proposed and other existing multi-band antennas.

\begin{tabular}{c|c|c|c|c}
\hline References & $\begin{array}{c}\text { Dimensions } \\
\text { in }(\mathrm{mm})\end{array}$ & No. of bands & Operation Frequencies $(\mathrm{GHz})$ & Gain $(\mathrm{dB})$ \\
\hline 12 & $70 \times 50$ & 4 & $2.1 / 2.45 / 3.5 / 5.8$ & $1.3 / 2.1 / 2.4 / 2.5$ \\
\hline 13 & $100 \times 35$ & 6 & $0.9 / 1.7 /(1.710-1.88) /(1.85-1.99) /(2.305-$ & $1.14 / 2.23$ \\
\hline 14 & $80 \times 30$ & 3 & $2.4) / 2.4$ & $4-5$ \\
\hline 15 & $30 \times 28$ & 4 & $2.45 / 3.5 / 5.8$ & $1.8 / 2.9$ \\
\hline 16 & $40 \times 35$ & 3 & $1.6 / 2.5 / 5.8 / 9.8$ & $1.92 / 3$ \\
\hline This Work & $20 \times 35$ & 4 & $2.45 / 3.5 / 5.4$ & $2.1 / 3 / 1.9 / 2.4$ \\
\hline
\end{tabular}




\section{Conclusion}

A compact C-shape with a multi-band tunable frequency-reconfigurable antenna has been fabricated and its performance has been experimentally verified. It consists of a monopole on the antenna face. The substrate has been chosen to be the commercial FR-4 with relative permittivity of 4.3 , the thickness was $1.6 \mathrm{~mm}$ and the loss tangent was 0.025 . The proposed antenna works in two modes with a single band and one mode with dual bands. The reconfigurability has been accurately achieved by switching (ON/OFF) the incorporated PIN-diodes. The designed antenna has found to effectively work in the following bands; 3G, 4G AWS1 (1700-2100 MHz), (WLAN) (2.45 GHz and $5 \mathrm{GHz})$ and WiMAX (3.5 GHz).

The good performance of the fabricated antenna in terms of $S_{11}$, radiation patterns, efficiency, and gain has been fully confirmed and it is found that the proposed antenna outperforms many existing antennas.

\section{References}

[1] X. L. Sun, S. W. Cheung and T. I. Yuk, "Dual-Band Monopole Antenna With FrequencyTunable Feature for WiMAX Applications," in IEEE Antennas and Wireless Propagation Letters, vol. 12, pp. 100-103, 2013.

[2] K. Wong and C. Chang, "Printed $\lambda / 8$-PIFA for internal penta-band mobile phone antenna," 2009 3rd European Conference on Antennas and Propagation, Berlin, 2009, pp. 533-537.

[3] Y. Dong, H. Toyao and T. Itoh, "Design and Characterization of Miniaturized Patch Antennas Loaded With Complementary Split-Ring Resonators," in IEEE Transactions on Antennas and Propagation, vol. 60, no. 2, pp. 772-785, Feb. 2012.

[4] S. Su, "High-Gain Dual-Loop Antennas for MIMO Access Points in the 2.4/5.2/5.8 GHz Bands," in IEEE Transactions on Antennas and Propagation, vol. 58, no. 7, pp. 2412-2419, July 2010.

[5] A. A. Eldek, A. Z. Elsherbeni, C. E. Smith and Kai-Fong Lee, "Wideband rectangular slot antenna for personal wireless communication systems," in IEEE Antennas and Propagation Magazine, vol. 44, no. 5, pp. 146-155, Oct. 2002.

[6] N. H. Gad, and M. Vidmar," Design of a microstrip-fed printed-slot antenna using defected ground structures for multiband applications", ACES Journal, Vol. 33, No. 8, Aug. 2018, pp. 854860 .

[7] H. U. Iddi, M. R. Kamarudin, T. A. Rahman and R. Dewan, "Design of dual-band B-shaped monopole antenna for MIMO application," Proceedings of the 2012 IEEE International Symposium on Antennas and Propagation, Chicago, IL, 2012, pp. 1-2.

[8] S. Jing, Y. Yin, A. Sun, Y. Wei and Y. Yang, "Compact E-shaped monopole antenna for dualband WLAN applications," 2011 IEEE International Conference on Microwave Technology \& Computational Electromagnetics, Beijing, 2011, pp. 305-308. 
[9] J. R. Panda and R. S. Kshetrimayum, "A printed F-shaped dual-band monopole antenna for RFID and WLAN applications," 2010 International Conference on Computer and Communication Technology (ICCCT), Allahabad, Uttar Pradesh, 2010, pp. 789-791.

[10] Lierong Wu, Jingjian Huang and Naichang Yuan, "Compact multiband monopole antenna for GPS/WLAN/WiMAX application," 2016 IEEE International Conference on Microwave and Millimeter Wave Technology (ICMMT), Beijing, 2016, pp. 618-620.

[11] K. M. Younus, K H. Sayidmarie "A Tri-Band Frequency Reconfigurable Slot Antenna for Wireless Applications”, ACES Journal, Feb. 2020.

[12] A. T. Abed and M. S. J. Singh, "Slot antenna single layer fed by step impedance strip line for Wi-Fi and Wi-Max applications," in Electronics Letters, vol. 52, no. 14, pp. 1196-1198, 772016.

[13] S. Thavakumar and M. Susila, "Design of multi resonant PIFA antenna for mobile telecommunication networks," 2017 International Conference on Wireless Communications, Signal Processing and Networking (WiSPNET), Chennai, 2017, pp. 2462-2465.

[14] Mansoul, A, Seddiki, ML, "Multiband reconfigurable Bowtie slot antenna using switchable slot extensions for WiFi, WiMAX, and WLAN applications, " Microw Opt Technol Lett 2018; 60: 413418.

[15] Ali Tet al., "A multiband reconfigurable slot antenna for wireless applications, "AEUInternational Journal of Electronics and Communications,2018, 84,273-280.

[16] S. A. A. Shah, M. F. Khan, S. Ullah and J. A. Flint, "Design of a multi-band frequency reconfigurable planar monopole antenna using truncated ground plane for Wi-Fi, WLAN and WiMAX applications," 2014 International Conference on Open Source Systems \& Technologies, Lahore, 2014, pp. 151-155. 